\title{
Requisitos para modelagem e acompanhamento de trabalhos síncronos e/ou assíncronos realizados por equipes: uma abordagem apoiada na Epistemologia Genética*
}

\author{
Claudia Brandelero Rizzi** \\ Antônio Carlos da Rocha Costa ${ }^{* * *}$ \\ Sérgio Roberto Kieling Franco ${ }^{* * * *}$ \\ Jorge Bidarra* \\ Cristina Yassue Morimotto ${ }^{* * * * *}$
}

\section{Resumo:}

O objetivo deste trabalho é relatar uma pesquisa que culminou na proposição de um de um conjunto de requisitos que visa modelar e acompanhar trabalhos realizados por equipes, fundamentados na Epistemologia Genética. Esses requisitos foram reunidos em um roteiro e este roteiro foi estruturado em três etapas: uma quando do planejamento do trabalho em equipe, outra quando da constituição das equipes, e outra quando do término dos trabalhos.

Palavras-chave: trabalhos em equipe, roteiro, epistemologia genética.

\section{Abstract:}

The objective of this work is to present a research that culminated in the proposition of a group of requirements whose objective is to model and to accompany works executed by teams, based in Genetic Epistemology. Those requirements were organized in a sequence of steps and this sequence of steps was structured in three stages: a when of the planning of the work in team, other when of the constitution of the teams, and other when of the end of the works.

Keywords: works in team, sequence of steps for works in team, genetic epistemology.

\section{Introdução e contextualização}

O objetivo deste trabalho é introduzir e discutir alguns princípios de um processo de modelagem de trabalhos em equipe, que incluem desde sua proposição até seu acompanhamento. Trata-se de uma proposta preliminar, fundamentada na Epistemologia Genética, que visa apoiar proponentes e executores em atividades que sejam realizadas por equipes. A título de organização, esses primeiros princípios foram reunidos em um

* Este artigo é parte do trabalho de tese intitulado "A cooperação na ação e uma especificação de requisitos para agentes e sistemas multiagente fundamentados na Epistemologia Genética", defendido em 24/03/2006, pelo Programa de Pós-Graduação em Informática na Educação da UFRGS.

** Nome: Claudia Brandelero Rizzi; qualificação profissional: docente; titulação de mais alto nível: doutorado em Informática na Educação; entidade em que trabalha: Universidade Estadual do Oeste do Paraná - UNIOESTE; cargo que ocupa: coordenadora da Divisão de Informática e Estatística do Núcleo de Inovações Tecnológicas ; endereço eletrônico: cbrizzi@unioeste.br; www.inf.unioeste.br.

*** Nome: Antônio Carlos da Rocha Costa; qualificação profissional: professor; titulação de mais alto nível: doutorado em Ciência da Computação; entidade em que trabalha: Universidade Católica de Pelotas; cargo que ocupa: Professor Adjunto; endereço eletrônico: rocha@atlas.ucpel.tche.br; http://rocha.ucpel.tche.br

${ }_{* * * *}$ Nome: Sérgio Roberto Kieling Franco; qualificação profissional: professor; titulação de mais alto nível: doutor em Educação; entidade em que trabalha: Universidade Federal do Rio Grande do Sul; cargo que ocupa: professor adjunto; endereço eletrônico: sergio.franco@ufrgs.br; www.pgie.ufrgs.br

${ }^{* * * * * *}$ Nome: Jorge Bidarra; qualificação profissional: professor adjunto; titulação de mais alto nível: doutor; entidade em que trabalha: Universidade Estadual do Oeste do Paraná - UNIOESTE; cargo que ocupa: professor; endereço eletrônico: jbidarra@unioeste.br; www.unioeste.br/nit

${ }^{* * * * * *}$ Nome: Cristina Yassue Morimotto; qualificação profissional: aluna do curso de Bacharelado em Informática da UNIOESTE; endereço eletrônico: crisymorimoto@yahoo.com.br.

V. $4 \mathrm{~N}^{\circ} 1$, Julho, 2006 
roteiro e este roteiro foi estruturado em três etapas: uma quando do planejamento do trabalho em equipe, outra quando da constituição das equipes, e outra quando do término dos trabalhos. Essas etapas são discutidas ao longo deste texto.

A principal constatação que motivou a listagem e organização destes primeiros princípios, doravante denominados simplesmente de roteiro, foi o fato de que tanto a vivência prática quanto a revisão bibliográfica mostram que existem diferentes tipos de trabalhos em grupos e estes apresentam uma maior ou menor variedade de variáveis que, muitas vezes, acabam por não ser levadas em conta, tanto por proponentes quanto por executores, talvez por serem consideradas como de senso comum.

Exemplos deste fato, e citando apenas trabalhos cuja fundamentação teórica decorre da Epistemologia Genética (visto ser ela que fundamenta este trabalho), são as obras de Constance Kamii e Rheta DeVries (1980), Anne Nelly Perret-Clermont (1987), Maria Lucia Faria Moro (1987), e Maria do Carmo Monteiro Kobayashi (2001).

Constance Kamii e Rheta DeVries organizaram uma obra em que tratam dos jogos como uma atividade importante para a criança, especialmente porque viabilizam o exercício de suas atividades, bem como de sua vida social. São apresentadas sugestões para a variação e novas concepções de oito tipos de jogos, e é dada especial importância para jogos em grupo (Kamii \& Devries, 1980).

Anne Nelly Perret-Clermont estudou o papel da interação social entre crianças no desenvolvimento do conhecimento. $\mathrm{O}$ sucesso das atividades propostas a pequenos grupos é explicado pelo "conflito sócio-cognitivo", que constitui o grau "ótimo" de divergências entre as opiniões dos componentes, o que lhes provoca novas coordenações de esquemas, a partir de pontos de vista diferentes (Perret-Clermont, 1987).

Tanto Maria Lucia Faria Moro (1987) quanto Maria do Carmo Monteiro Kobayashi (2001) trabalharam com grupos de crianças, a primeira focando a construção da geometria, e a segunda, a interação social entre elas.

O que esses trabalhos têm em comum é o fato de que utilizaram grupos de crianças para estudar ou propor interações do tipo sujeito/sujeito. Apesar disso, tanto na sugestão de trabalhos em grupos para fins pedagógicos quanto em sua utilização enquanto objeto de pesquisa quando se pretende efetuar análises de aspectos cognitivos particulares (a exemplo do que fazia Piaget, e o que geralmente fazem aqueles que nele se inspiram), nota-se que não há uma estruturação detalhada sobre as atividades conjuntas. Ou seja, há planejamento, mas não a preocupação de explicitar características da constituição e do trabalho das equipes, tais como as regras utilizadas (para além daquelas previstas nas atividades), os valores em jogo, a linguagem e os sinais empregados, os compromissos assumidos, a autonomia dos partícipes, os papéis que exercem, a dinâmica das trocas, dentre outros.

Uma exceção a esta prática é encontrada em "O Juízo Moral na Criança”, que parece ser a única obra de Piaget na qual ele trabalhou com grupos de crianças. Nela, Piaget parte de entrevistas com alunos de escolas de Genebra e Neuchâtel especialmente sobre problemas morais, mas também sobre representação do mundo e causalidade. Um de seus objetivos era o de identificar a noção de "respeito à regra" do ponto de vista da criança. Por este motivo estudou e analisou as regras do jogo social, visto serem elas obrigatórias para a consciência do jogador honesto. Estudou e analisou também os princípios provenientes das relações entre crianças (Piaget, 1994).

Apesar deste objetivo específico, Piaget preocupou-se com questões como as regras do jogo, o respeito a elas, a autonomia dos participantes (as regras foram elaboradas apenas por crianças), as relações entre as crianças, o ambiente onde as atividades foram desenvolvidas, a linguagem e os sinais utilizados, as características de cada grupo, incluindo individuais, os valores envolvidos, etc. Porém, estas e outras informações 
estão dispersas pelo texto e podem até passar despercebidas. Mas, para alguém que queira propor ou utilizar grupos de trabalho, elas são relevantes, e procurou-se inclui-las como parte integrante do roteiro apresentado neste trabalho.

A seguir são feitas algumas colocações quanto a conceitos e posicionamentos teóricos, a começar pelo fato de que existe diferença entre os conceitos de grupo e equipe. Entendese, por grupo de trabalho, o conjunto de dois ou mais indivíduos que estão unidos por algum motivo (Martins, 2005). Ainda para este mesmo autor, equipe é o conjunto de dois ou mais indivíduos que têm objetivos em comum, trabalham para o mesmo propósito e, por este motivo, geralmente cooperam entre si.

Carlos Piacastelli e colaboradores qualificam ainda mais o significado do trabalho em equipe. Para eles, equipe é o conjunto "[...] de pessoas com habilidades complementares, comprometidas umas com as outras pela missão comum, objetivos comuns (obtidos pela negociação entre os atores sociais envolvidos) e um plano de trabalho bem definido" (Piacastelli, Faria \& Silveira, 2005). Note-se que, por este conceito, reconhece-se, em uma equipe, a diversidade de conhecimentos e habilidades de seus integrantes, o que possibilita que se complementem e enriqueçam conjuntamente, contribuindo para que as chances de sucesso de seu trabalho sejam maiores. Por este conceito se identifica a existência de um plano sobre como alcançar os objetivos definidos pela equipe.

Outra questão, também apontada por esses autores, é que se tem agregado, à noção de trabalho em equipe, a idéia de que, no processo de desenvolvimento de suas atividades em busca de seus objetivos, seus componentes devem criar as condições necessárias para o crescimento, tanto individual quanto do próprio grupo.

Por sua vez, Piaget utiliza em francês o termo "équipe", cuja tradução para o português é equipe ou time. Particularmente em seu artigo "O trabalho por équipes na escola" (Piaget, 1996), ele discorre sobre as origens deste tipo de trabalho, os motivos para utilizá-lo em atividades pedagógicas, dentre outros assuntos interessantes. O que se quer frisar aqui é a maneira como Piaget julga que ele deva ser conduzido. E é este aspecto que se quer relacionar com o conceito de equipe dado por Piacastelli e colaboradores.

Para Piaget, o trabalho em equipe deve ser conduzido através do denominado método ativo. O método ativo é aquele que confere grande importância ao trabalho de pesquisa "[...] exigindo-se que toda verdade a ser adquirida seja reinventada pelo aluno, ou pelo menos, reconstruída e não simplesmente transmitida." (Piaget, 1973a, p. 18).

Ele afirma ainda, neste mesmo texto, que o proponente deste tipo de atividade deve criar situações iniciais capazes de suscitar problemas úteis aos participantes. Deve organizar contra-exemplos que os conduza à reflexão e os estimule à pesquisa e ao esforço. Quanto ao esforço, Piaget afirma que

[...] o interesse não exclui de forma alguma o esforço. Muito pelo contrário. É que uma educação que prepara para a vida não consiste em substituir os esforços espontâneos pelos esforços feitos com ajuda, porque se a vida implica uma parte não negligenciável de trabalhos impostos ao lado de iniciativas mais livres, as disciplinas necessárias permanecem mais eficazes quando livremente aceitas sem este acordo interior. Os métodos ativos não levam, de forma alguma, a um individualismo anárquico, mas, principalmente quando se trata de uma combinação de trabalho individual e do trabalho por equipes, a uma educação da autodisciplina e do esforço voluntário. (PIAGET, 1998, p. 74-75).

O proponente do trabalho em equipe, ainda segundo Piaget, deve conduzir seus executores a ultrapassar as fronteiras dos observáveis a fim de elaborarem composições de produções, visto que o fundamental não é apenas o fenômeno ou o observável, mas a estrutura subjacente que pode ser reconstruída por dedução. Deve orientar no sentido de que os participantes tomem consciência das questões centrais dos temas abordados, uma vez que, dada a complexidade do conhecimento humano acumulado, seria totalmente 
impróprio esperar que os participantes elaborassem por si sós, com exatidão, tais conhecimentos.

Defende que o proponente planeje seu trabalho de modo interdisciplinar, ou seja, que cada especialidade ou disciplina deva ser abordada de maneira que generalize suas estruturas particulares e as aplique em situações englobando outras disciplinas. O proponente deve, portanto, sem negligenciar o campo de sua especialidade, orientar o estudante a perceber, de maneira continuada, as relações existentes entre as disciplinas.

Ora, se essas são, do ponto de vista de Piaget, as condutas esperadas por parte do proponente de trabalhos em equipe, quais são as condutas esperadas por parte da equipe? Uma das respostas parece ser aquela dada por Piacastelli e colaboradores, corroborada através de experimentos realizados com pré-adolescentes (Rizzi, 2006), em momento anterior ao da proposição do roteiro aqui apresentado.

Esses autores identificam que os indivíduos componentes de equipes geralmente têm conhecimentos e habilidades que, mesmo sendo diferentes (provenientes de áreas diferentes), as utilizam complementarmente. Que estejam efetivamente comprometidos com os mesmos objetivos, mas que esses objetivos não sejam simplesmente impostos, mas debatidos, negociados e, enfim, assumidos por todos. E que, também juntos, definam e sigam planos para atingir tais objetivos.

Assim, assumindo que os proponentes de trabalhos em equipe tenham conhecimento, motivação e esforço para conduzir trabalhos desta natureza, aos moldes do que foi exposto, que o grupo se concretize em termos de uma equipe, o roteiro apresentado a seguir parece ser um instrumento útil tanto na proposição quanto no acompanhamento de tais trabalhos. As próximas seções são dedicadas a apresentá-lo e discuti-lo.

\section{0 roteiro: etapas, comentários e sugestão de utilização}

Este roteiro foi idealizado para ser executado em três etapas. A primeira é realizada pelos proponentes do trabalho em equipe e constitui o seu planejamento. A segunda e a terceira etapas são realizadas pela equipe de trabalho e correspondem, respectivamente, à constituição e definição dos trabalhos que serão feitos por ela, e uma análise individual de todo o trabalho. Estas etapas são apresentadas nas próximas seções.

\subsection{O planejamento do trabalho em equipe: a proposição inicial}

Sugere-se que os proponentes do trabalho em equipe façam um planejamento prévio de seu trabalho. Isto lhes propicia maiores condições de intervir, tanto técnica e metodologicamente, quanto com relação a seu delineamento, uma vez que são diversas as variáveis que estão em jogo em tais situações.

Esta sugestão parece ser um tanto quanto desnecessária em se tratando de atividades didáticas, uma vez que o planejamento faz parte da prática pedagógica cotidiana. Considerando, contudo, que algumas das variáveis presentes em trabalhos desta natureza podem não receber a atenção devida, elaboraram-se algumas questões que, sugere-se, sejam levadas em conta pelos proponentes de trabalhos em equipe, antes de sua proposição propriamente dita.

Ao listar estas questões não se pretende propor um receituário, ou uma seqüência de passos supostamente "infalíveis", ou mesmo interferir em uma prática, já enraizada e bastante comum em atividades pedagógicas (a de propor e realizar trabalhos em equipes). $\mathrm{O}$ que se pretende é sugerir que se inclua, no planejamento de trabalhos em equipe, a reflexão sobre algumas questões que possam contribuir para a melhor proposição e condução deste tipo de trabalho. As questões sugeridas para serem respondidas nesta primeira etapa são apresentadas na Tabela 1, mostrada a seguir. 
Tabela 1 - Formulário para planejamento de atividades em equipe

\section{Planejamento de trabalhos em equipe}

\section{Proponentes:}

1) Qual é o tema e os objetivos deste trabalho em equipe?

2) Qual é o estado da arte e os métodos e técnicas empregados no estudo deste tema?

3) No contexto do tema, que abrangência e profundidade se espera que os participantes atinjam?

4) Que habilidades se espera suscitar e/ou exercitar com este trabalho?

5) Quais as chances de que o tema proposto para o trabalho em equipe seja interessante para os participantes? Como fazer com que cada indivíduo tenha prazer em participar do trabalho?

6) Os participantes poderão optar pela maneira com que conduzirão o trabalho, incluindo subtemas? Como garantir que questões centrais do tema sejam contempladas?

7) Os participantes poderão constituir livremente suas equipes? As equipes têm histórico de trabalho conjunto? Se sim, é interessante que continuem juntas?

8) Que características contribuiriam para que a equipe realizasse melhor este trabalho (número de componentes, mais homogênea ou heterogênea, cooperação, coordenação, negociação, formas de organização, papéis, etc.)?

9) Quais são os recursos (equipamentos, material bibliográfico, etc.) para a execução do trabalho? Eles são limitados?

10) Como viabilizar as interações entre as equipes (encontros presenciais, a distância, situações síncronas e/ou assíncronas, etc.)?

11) Que atitudes, por parte dos proponentes, podem contribuir para o sucesso do trabalho das equipes?

12) Quais seriam as melhores maneiras para avaliar as equipes?

Observações.

\subsection{A constituição da equipe: as definições do trabalho}

A segunda parte deste roteiro é destinada à constituição, modelagem e elaboração do planejamento das atividades que deverão ser feitas pela equipe. Trata-se de oito questões que, sugere-se, sejam discutidas, negociadas e definidas pelos integrantes de cada equipe. $\mathrm{O}$ formulário mostrado a seguir, ilustrado na Tabela 2 , sintetiza essas questões. Seu preenchimento é feito pela equipe, e sugere-se que uma cópia seja entregue aos proponentes do trabalho.

No decorrer do desenvolvimento do trabalho em si, adaptações são comuns, frutos do dinamismo do processo de trabalho. Nesses casos, a equipe e os proponentes devem estar cientes dos motivos que levaram a elas. Voltar ao roteiro e efetuar essas alterações pode ser uma atitude interessante a ser realizada pela equipe, implicando inclusive, maior entendimento do trabalho por parte daqueles que o irão realizar.

Essas oito questões são retomadas a seguir de maneira mais detalhada, em a comparando com as questões elaboradas para o planejamento por parte dos proponentes de trabalhos em equipe. Associadas a estas questões estão explicações e comentários. Isto se deve ao fato de que são questões fundamentais no que se refere à tentativa de melhor e nortear o trabalho da equipe. 
Tabela 2 - Formulário de constituição, modelagem e elaboração do planejamento de atividades de trabalhos em equipe

Formulário de constituição, modelagem e elaboração do planejamento de
atividades de trabalhos em equipe

1) Objetivo geral do trabalho (O que o proponente do trabalho deseja que a equipe realize, experimente, conheça?):

2) Componentes da equipe: $\quad$ Objetivo individual (O que é importante para mim?):

1)

2)

1)

2)

3)...

3) ...

3) Tomando como referência as definições das duas questões anteriores, definir em conjunto os objetivos da equipe ( $\mathrm{O}$ que seria importante para todo a equipe?):

4) Qual o conhecimento que a equipe possui sobre o trabalho ( $O$ que se sabe a respeito?).

habilidades ( $\mathrm{O}$ que eu sei fazer que pode ajudar a equipe?): Componentes da equipe:

1)

2)

1)

2)

3)...

3)...

5) Definir as regras para elaboração do trabalho (Que valores - morais, éticos, estéticos, etc., - uma equipe deve possuir, e comprometer-se com ela, para que suas chances de sucesso aumentem?).

6) Definir os elementos que viabilizam a comunicação na equipe e como serão utilizados (Quais meios de comunicação - linguagem, símbolos, sinais, etc. - serão utilizados pelos membros da equipe? Em se tratando de telefone, fax e encontros presenciais, definir melhores dias/horários).

7) Definir os recursos necessários (Quais recursos materiais, bibliográficos, técnicos, etc., a equipe precisará para atingir seu objetivo?).

8) Elaborar a descrição dos planos e o respectivo conjunto de tarefas para sua execução (Como, quem e quando faremos as tarefas planejadas?).

Alocação das tarefas aos componentes: Cronograma de execução (prazo de entrega):

1)

2)

1)

2)

3)...

3)...

1) Identificar o tema e definir o objetivo geral do trabalho

Nesta questão, a equipe deve identificar o tema ao qual o trabalho está relacionado, bem como definir o seu objetivo. Em alguns casos, um ou mais temas são propostos e deixados a critério dos grupos a escolha do enfoque, delineamento ou objetivo. Mesmo nestes casos a equipe deve explicitar o tema e o objetivo geral do trabalho. Ter acesso ao objetivo geral da equipe de maneira explícita permite que eles possam ter melhores condições de avaliar e tomar decisões a respeito.

2) No contexto do objetivo geral do trabalho, cada participante deve explicitar e definir seu objetivo individual

Depois de ter sido identificado o tema e definido o objetivo geral do trabalho (questão 1), cada participante deve definir seus objetivos individuais, visto que cada um possui valores únicos, individuais. Isto faz com que seus objetivos, interesses e consequiente motivação sejam também individuais. Se cada participante explicitar, a partir do contexto do objetivo geral, seus objetivos específicos, a equipe terá maior clareza com relação às motivações de cada componente e, assim, terá melhores condições de extrair daí subsídios para construir uma solução conjunta que, além de atender à especificação 
do objetivo geral, atenda também aos anseios individuais de seus integrantes. Este tipo de discussão pode também desencadear os sentimentos de respeito mútuo, igualdade e reciprocidade, fundamentais em atividades coletivas, visto que faz com que os integrantes do grupo se exponham mais a seus companheiros. $\mathrm{O}$ que se pretende, portanto, é fazer propiciar um momento de reflexão e síntese conjunta, a fim de compatibilizar os objetivos individuais com os objetivos gerais da equipe. Se isso acontece, pode-se inferir que ela trabalha de maneira mais coesa e motivada.

3) Tomando como referência as definições das duas questões anteriores, definir em conjunto os objetivos da equipe

Nesta questão a equipe deve definir em conjunto seus próprios objetivos. Esta fase envolve negociação, visto que, em muitos casos, não é possível contemplar todos os interesses individuais. Isto pode decorrer de diversos motivos, dentre eles, a escassez de recursos, o que inclui o fator tempo. O que interessa é que a equipe defina, em conjunto e de maneira autônoma, os objetivos que deverão ser atingidos através do trabalho que será realizado por ela.

4) Pontuar o conhecimento que a equipe possui (no momento) sobre o trabalho, e explicitar as habilidades dos participantes

Esta questão está dividida em duas partes distintas: a primeira diz respeito ao conhecimento do grupo sobre o tema do trabalho, e a segunda sobre as habilidades de cada um dos participantes. Na primeira parte, a equipe deve refletir e sistematizar o conhecimento que possui sobre o trabalho. É a ocasião em que verifica, por exemplo, se algum dos componentes tem visão do todo, ou se conhece particularidades do tema, ou se sabe sobre alguma referência que possa ser importante para toda a equipe. É assim que todos os membros passam a se identificar com relação ao conhecimento, inclusive técnico, que cada companheiro possui. A segunda parte visa fazer com que cada membro da equipe exponha e, posteriormente, relacione suas habilidades tendo em vista o objetivo a ser alcançado.

A relação dos conhecimentos e das habilidades servirá não apenas para possibilitar que haja maior conhecimento sobre cada um dos membros da equipe, mas também para sistematizar informações que serão utilizadas na última etapa deste roteiro. Este é o momento da tomada de consciência sobre o conhecimento e as habilidades de cada membro da equipe, e permite vislumbrar as possibilidades de composições entre elementos como possibilidades potenciais de atividades futuras. Além disso, a equipe começa a ter uma noção maior sobre as dimensões do trabalho que deverá executar.

De modo geral, esta etapa viabiliza a organização das equipes. Pode ser, por exemplo, que exista um integrante que tenha maior conhecimento sobre o tema e, portanto, possa ser o líder. Podem formar subequipes, dependentes ou independentes. Podem trabalhar de maneira parcialmente isolada ou cooperativa. É assim também que podem ficar evidenciados os papéis que cada membro da equipe irá desempenhar.

\section{5) Definir as regras valores para elaboração do trabalho}

Nesta fase são definidas as regras que serão utilizadas no desenvolvimento do trabalho. Para isso, os componentes explicitam os requisitos considerados por eles como imprescindíveis para que um trabalho em equipe seja realizado com sucesso. Note-se que, ao assim proceder, cada componente precisa recorrer à sua escala de valores pessoal, visto que é dela que esses requisitos decorrem. Por exemplo, algum membro da equipe pode considerar que a responsabilidade e o empenho sejam fundamentais. Outro, que são os compromissos e a pontualidade. Enfim, tendo apresentado e discutido esses requisitos, procede-se à elaboração de uma relação dos aspectos mais valorizados pelos elementos da equipe. Esta relação dever ser assumida e seguida por eles como as regras daquela equipe de trabalho. São elas que contribuirão para reduzir os conflitos e parametrizar as condutas. 
6) Definir os elementos que viabilizam a comunicação no grupo

Nesta fase do roteiro são definidos os elementos que viabilizarão a comunicação entre os membros da equipe. Para isso, é feita uma relação identificando cada indivíduo e os respectivos elementos de comunicação com os quais a equipe pode contar e utilizar. Pode-se definir, por exemplo, que a linguagem comum será o português, que, para se comunicar, os membros da equipe podem utilizar e-mail, fórum de discussões, telefone, e fax. Se residirem na mesma cidade, podem marcar encontros, o que facilita a comunicação oral presencial. A comunicação é a base para as interações, negociações, planejamento, cooperação, enfim das organizações sociais, além de ser o meio para coordenar ações.

\section{7) Definir os recursos necessários}

Nesta fase do roteiro são discutidos e identificados os recursos necessários para a realização do trabalho. Esses elementos podem ser bibliográficos, trabalhos práticos, experimentos, utilização de máquinas e equipamentos específicos, etc. Por exemplo, a equipe pode precisar gerar um relatório escrito onde constem figuras e gráficos. Para isso, ela deve ter acesso a recursos bibliográficos, e utilizar um editor de textos para nele sistematizar o trabalho realizado. Pode-se concluir que, para este trabalho, é preciso ter acesso a pelo menos um computador conectado à web e equipado com um editor de textos, um escanner, e uma impressora.

\section{8) Elaborar a descrição dos planos, a alocação das tarefas e o cronograma de execução}

Nesta fase do roteiro são definidos os planos que deverão ser executados pelos integrantes da equipe, além da alocação individual ou coletiva de tarefas, bem como os prazos estabelecidos para tal. É nesta etapa, portanto, que os indivíduos assumem compromissos conjuntos sobre as ações da equipe visto que estarão envolvidos não apenas enquanto elementos individuais, mas também como componentes de uma organização maior, a própria equipe.

\subsection{0 término do trabalho em equipe: a avaliação individual}

A última parte deste roteiro é destinada à análise e avaliação das atividades feitas pela equipe. São oito questões que, sugere-se, sejam respondidas individualmente pelos membros da equipe. Note-se que a atividade anterior, que inclui a constituição, modelagem e elaboração do planejamento das atividades dos trabalhos da equipe, foi feita em conjunto por ela, e esta etapa, a de análise e avaliação, é individual.

Isto porque, tanto a análise quanto a avaliação das atividades realizadas decorre de uma perspectiva pessoal, única, influenciada pelos valores pessoais. É claro que o diálogo na equipe pode construir um consenso sobre essas atividades. Do ponto de vista deste roteiro, é importante oportunizar a proponentes e executores a possibilidade de refletirem sobre o trabalho em equipe sob o ponto de vista individual, ou seja, de cada integrante dela. $\mathrm{O}$ formulário mostrado a seguir, ilustrado na Tabela 3 , sintetiza as oito questões componentes desta última parte do roteiro.

Tabela 3 - Formulário de análise e avaliação das atividades do trabalho em equipe Formulário de análise e avaliação das atividades do trabalho em equipe

1) Identificação do indivíduo e da equipe a que pertenceu (Meu nome, nome da equipe). 2) Identificação do tema e/ou objetivo do trabalho proposto pelo proponente do trabalho em equipe (Qual foi o tema ou objetivo proposto pelo proponente do trabalho em equipe?). 
3) Identificação dos objetivos individuais originais decorrentes (Quais eram meus objetivos pessoais quando da proposição deste trabalho em equipe?).

4) Identificação dos objetivos específicos determinados pela equipe (Quais foram os objetivos específicos deliberados pela equipe?).

5) Memorial das atividades realizadas pela equipe (Relato histórico das atividades feitas pela equipe, se possível, nomeando os responsáveis pelas subatividades, com impressões e críticas pessoais a respeito).

6) Relato das principais dificuldades enfrentadas com a realização do trabalho (Que dificuldades eu e minha equipe tivemos? Por quê? Como as solucionamos?).

7) Relato dos principais aspectos proporcionados pela realização do trabalho em equipe em termos de conhecimento e de vida (O que eu aprendi com este trabalho? Como este trabalho contribuiu para minha experiência de vida?).

8) Comentários gerais (Que críticas, sugestões, observações tenho a fazer sobre o trabalho?).

\section{Comentários finais}

Os primeiros princípios de um processo de modelagem de trabalhos em equipe, apresentado neste artigo, são frutos de observações e relações estabelecidas a partir de estudos e pesquisas realizados durante o curso de doutorado de um dos autores, e acompanhado pelos demais, que direta ou indiretamente, trabalharam (orientaram) em sua elaboração e/ou estão trabalhando em sua verificação.

Esses princípios (e por isso mesmo denominados "primeiros princípios") constituem a organização de uma proposta de roteiro que, devido ao fato de que sua sistematização ter ocorrido em fase tardia do período destinado à conclusão da tese, não foram experimentados e criticados, ou seja, não passaram pelo crivo de um trabalho científico. Esta etapa, a da verificação das proposições aqui contidas, já foi iniciada, mas se encontra ainda em fase inicial cujos resultados serão divulgados em momento oportuno.

$\mathrm{O}$ roteiro aqui proposto foi idealizado tendo como suporte teórico a Epistemologia Genética. Isto não significa que proponentes executores devam, necessariamente comungar com esta concepção teórica. No entanto, considerando a complexidade das relações que são estabelecidas quando da proposição e execução de trabalhos em grupo, entende-se ser pertinente o emprego de instrumentos metodológico-pedagógicos como o roteiro apresentado neste artigo, enquanto elemento de apoio a este tipo de atividade. Além disso, trata-se de uma proposta viável e interessante também pelo fato de constituir um instrumento intuitivo e de fácil utilização.

Pode-se inferir que a proposição e realização de um trabalho em equipe com este tipo de concepção e ação tende a conduzir à cooperação efetiva, seja ela satisfatória ou não para seus integrantes. A cooperação insatisfatória é aquela que envolve apenas alternância e sincronização de operações, ou seja, a simples execução de atividades, o cumprimento de requisitos mínimos exigidos. A cooperação satisfatória, como disse Piaget, modifica os indivíduos dela participantes de maneira durável (Piaget, 1973).

Pode-se constatar, mesmo ainda empiricamente, que esta prática viabiliza que sejam evidenciados valores dos participantes de trabalhos em equipe. Os valores são noções qualitativas (PIAGET, 1973) construídas e utilizadas especialmente a partir e no convívio social. Eles decorrem de diversas fontes, tais como gostos individuais, interesses, valores coletivos como a moda, a posição social, regras morais, jurídicas, etc., ou seja, são noções subjetivas, e, como tal, não há como defini-los ou mensurá-los com exatidão, porém, eles se organizam em escalas, as "escalas de valores". Uma escala de valores é uma relação ordenada de valores em uma seqüência de importância, organizada e mantida particularmente nas relações sociais, e válida para um indivíduo, 
um grupo de indivíduos, ou uma sociedade inteira. As escalas de valores estão presentes em todas as sociedades, em maior ou menor grau e número. Elas são variáveis, heterogêneas, porém duráveis em um dado período de tempo e, portanto, é possível analisá-las enquanto válidas para um momento sincrônico. Para Piaget, a importância da escala de valores para um indivíduo é tal, que ele afirma que

[...] para cada indivíduo, segundo as finalidades que ele se propõe atingir e os meios que emprega ou conta empregar no prosseguimento destas finalidades, todos os objetos e todas as pessoas que o interessam (inclusive ele mesmo), assim como todas as ações, trabalhos e de forma geral, todos os "serviços" atual ou virtualmente prestados por eles, são suscetíveis de serem avaliados e comparados segundo algumas relações de valores, relações que constituem precisamente uma escala. (PIAGET, 1973, p. 117).

Mesmo sendo subjetivos, os valores dos indivíduos integrantes de equipes devem ser levados em conta, dada sua importância. Oportunizar situações em que os valores são explicitados pode propiciar condições de trabalho muito mais claras, honestas e produtivas.

Cabe dizer ainda que os valores, como os conhecimentos, podem ser aprimorados ao longo do processo de interação do indivíduo. Significa que, em um momento, determinado componente da equipe pode não ter uma participação ativa, produtiva, contributiva, etc. Propiciar situações de interações como esta, contudo, podem contribuir para a modificação deste indivíduo, de maneira que, na próxima interação, tenha conduta e conhecimento positivamente diferenciados.

\section{Referências Bibliográficas}

KAMII, C.; DEVRIES, R. Jogos em grupo na educação infantil. São Paulo: ArtMed, 1980.

KOBAYASHI, M.C.M. A construção da geometria pela criança. Marília: Cadernos de Divulgação Cultural, 2001.

MARTINS, R. Superação: o poder da conquista! Disponível em: <http://carreiras. emprego.com.br/comunidades/rh/artigos/050405-superacao_conquista.shtm>. Acesso em: 29 set. 2005.

MORO, M.L.M. Aprendizagem operatória: a interação social da criança. São Paulo: Cortez, 1987.

PERRET-CLERMONT, A. A construção da inteligência pela interacção social. Lisboa: Socicultur, 1978.

PIACASTELLI, C.; FARIA, H.; SILVEIRA, M. O trabalho em equipe. Disponível em: <http://www.opas.org.br/rh/publicacoes/textos apoio/Texto 1.pdf > . Acesso em: 29 set. 2005.

PIAGET, J. Estudos sociológicos. Rio de Janeiro: Editora Forense, 1973.

PIAGET, J. O juízo moral na criança. 2a ed. São Paulo: Summus Editorial, 1994.

PIAGET, J. O Trabalho por équipes na escola. In: Revista Psicopedagogia. (S.l): Salesianas, v. 15, n. 36, 1996. p. 14-20.

PIAGET, J. Para onde vai a educação? Rio de Janeiro: José Olympio, 1973a.

PIAGET, J. Psicologia e pedagogia. Rio de Janeiro: Forense Universitária, 1998.

RIZZI, C.B. A cooperação na ação e uma especificação de requisitos para agentes e sistemas multiagentes fundamentadas na epistemologia genética. Porto Alegre: PGIE/UFRGS, 2006. 